\title{
A Residential PHEV Load Coordination Mechanism with Renewable Sources in Smart Grids
}

\author{
Raul Martinez Oviedo ${ }^{\mathrm{a}}$, Zhong Fan ${ }^{\mathrm{a}}$, Sedat Gormus ${ }^{\mathrm{a}}$, Parag Kulkarni ${ }^{\mathrm{a}}$ \\ ${ }^{a}$ Toshiba Research Europe Ltd., Telecommunication Research Laboratory, 32 Queen Square, Bristol BS1 4ND, UK.
}

\begin{abstract}
A high penetration of Plug-in Hybrid Electric Vehicles (PHEVs) can lead to stress and overload in distribution systems when uncoordinated charging is considered. Thus, coordination mechanisms to manage PHEV charging during peak periods are needed. This paper evaluates the impact of PHEVs in the residential distribution grid and proposes a coordination mechanism based on heuristic rules as a load shaping tool. The impact of the mechanism on user convenience is also studied, and the benefits of having a renewable generation system is examined. Results show that our coordination mechanism is able to prevent the overloading of the distribution transformer. Further, it has been found that the performance of the renewable system (e.g., renewable fraction and renewable cost ratio) depend on many factors such as weather, region, equipment specification, and user preference.
\end{abstract}

Keywords: Demand response, load control, PHEV, smart grids, feed-in tariff

\section{Introduction}

Achieving a more efficient use of energy in residential grids has become of increasing importance for economic, environmental and energy conservation reasons. This has encouraged moving from a traditional electricity grid to a smart grid with Demand Response (DR) capabilities. Smart grids can support, based on a reliable communication infrastructure, the integration of renewable generation systems and variable pricing schemes to manage loads in the distribution system more efficiently [1]. Several efforts are currently underway in Europe, the US and Asia to deploy smart grids.

The increasing price of conventional fuel and oil, as well as environmental concerns, are also encouraging the adoption of Plug-in Hybrid Electric Vehicles (PHEVs) [2] [3]. PHEVs represent a new

Email addresses: raul .martinez@toshiba-trel.com (Raul Martinez Oviedo), zhong . fan@toshiba-trel .com (Zhong Fan), sedat.gormus@toshiba-trel.com (Sedat Gormus),parag.kulkarni@toshiba-trel.com (Parag Kulkarni) 
significant type of load on distribution systems. The charging process of these vehicles can demand a great amount of energy during long periods depending on the battery specifications. Thus, a high penetration of PHEVs in the vehicle market could severely impact the distribution grids causing overloads in the distribution transformers. This is particularly true when considering the scenario in which multiple PHEVs are charging during peak hours. To address this challenge, distribution systems need to be adapted to support the new load by implementing coordination mechanisms that allow them to manage PHEV charging efficiently.

In this paper we evaluate the impact of charging multiple PHEVs in residential distribution networks with a smart grid infrastructure. A coordination mechanism to manage PHEV charging is proposed based on heuristic rules and taking into account user priority in charging. The performance of the proposed mechanism is evaluated, as well as the impact it has on user convenience. The study also presents a model of a smart grid system integrating renewable generation capabilities and including realistic data of significant factors such as: electricity pricing, appliances activation time, driving habits, solar radiation and wind speed during the year, feed-in tariff, etc.

\subsection{Related work}

In the literature, several works have been found regarding managing PHEV battery charging and evaluating the impact of PHEV penetration in distribution networks.

In [4], the authors evaluate the impact of charging multiple PHEVs on residential distribution networks with different charging strategies. Their results reveal that a high penetration of PHEVs will create new load peaks that in some cases may overload the distribution transformer. In another work [5], the same authors introduce a load shaping tool based on DR strategy to mitigate the impact of EV in the distribution grid. Their strategy takes into account customer preferences, comfort level and load priority. Their proposed shaping tool is able to manage the total demand, preventing the transformer from being overloaded. However, in these works the system studied is limited to a residential transformer serving three homes and does not consider renewable generation systems deployed in user premises.

In [6] a comprehensive approach for evaluating the impact of different levels of PHEV penetration on distribution networks is proposed. Their results show that a high penetration of PHEVs leads to an increasing investment cost and energy losses in the distribution network. In [7], PHEV charging is treated as a demand side management (DSM) problem and two solutions have been proposed: a multi-agent 
systems (MAS) solution and an optimal quadratic programming (QP) scheduler solution. While the QP scheduler is able to optimally flatten peak loads and sufficiently charge PHEVs, it is not scalable. The MAS solution is shown to be scalable and adaptable to incomplete and unpredictable information. The authors of [8] have shown that we can take advantage of PHEV charging to mitigate the intermittency effect of renewable energy generation. A decision tool has been developed for the coordination of PHEV charging.

The integration of renewable systems in the management of PHEV batteries in smart grids is addressed by a number of papers, e.g. [9] [10]. In [9] the authors propose a control mechanism based on a cyber-physical power infrastructure and heuristic rules to coordinate the use of renewable energy and PHEV battery charging. Their model only considers solar energy source. A similar work is reported in [11], in which an enhanced model of a distribution system is adopted to include additional renewable sources. Also, the authors evaluate the effect failures in the communication infrastructure have on the survivability of the distribution system. Finally, there is a rich literature on demand response and demand side management [12] [13] [14]. For example, the authors of [12] present a demand dispatch algorithm for smart charging of PHEVs.

The contributions of this work, in comparison with some of the related works examined, can be summarized as follows:

1. We present a more realistic model of a residential distribution grid with renewable sources of energy. This includes realistic modeling of seasonal weather conditions, activation of appliances, and PHEV driving habits and plug-in time.

2. We propose an efficient load coordination mechanism, based on heuristics, to control the PHEV battery charging process avoiding the overload of distribution transformers. The proposed mechanism considers user preference in the charging process, management of the energy provided by renewables, and flexible policy definitions to prioritize the vehicle charging.

\subsection{Organization of this paper}

The rest of this paper is organized as follows. In Section 2 the smart grid system studied is introduced. In Section 3 the current distribution system is analyzed in terms of transformer load profile, and the impact of adding PHEVs as part of the loads is evaluated. In Section 4 the proposed load coordination mechanism is described. In Section 5 we present the simulation results regarding the performance of the coordination 
mechanism, an example of the coordination mechanism operation in a particular scenario, the impact on user convenience, and the efficiency and benefit of the renewable generation system. Finally, Section 6 summarizes the main conclusions derived from this work.

\section{System studied}

The system considered in this work consists of a residential neighborhood of five houses served by a $25 \mathrm{kVA}$ distribution transformer as illustrated in Figure 1 A typical distribution transformer has a rated power of $23.75 \mathrm{~kW}$ and can range between $25 \mathrm{kVA}$ to $75 \mathrm{kVA}$ per phase. It is normally able to serve between four to seven homes [4].

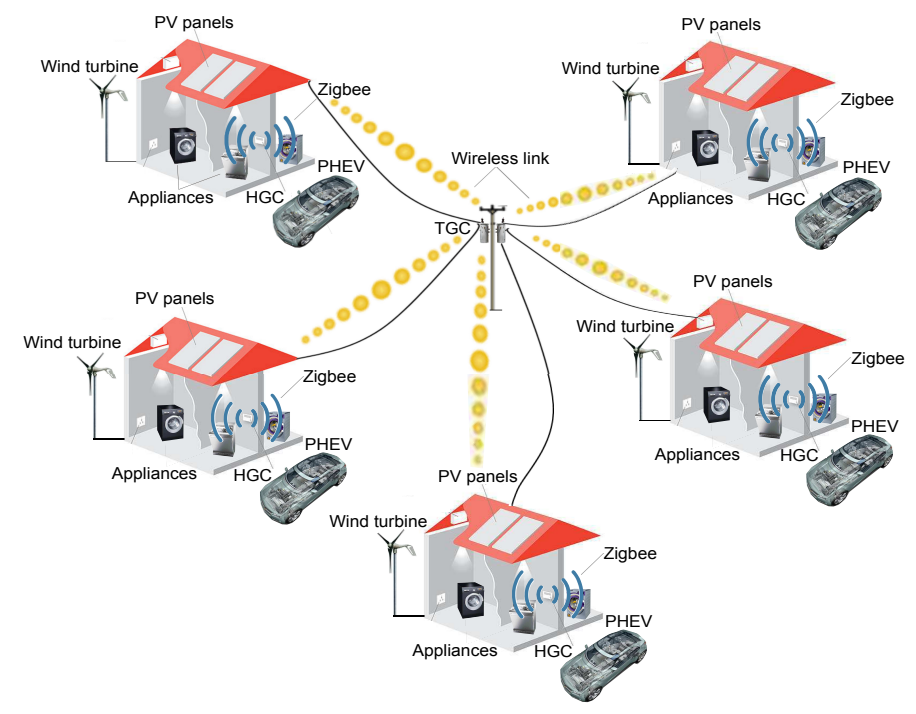

Figure 1: Residential smart grid system: five smart homes with three appliances and a PHEV served by a $25 \mathrm{kVA}$ transformer

Each house is considered to have a standard load profile that includes most common appliances, based on the information provided by [4]. In particular, we focus on three appliances (washing machine, dish washer and tumble dryer) and a PHEV per home for their random activation and charging respectively during a day. Appliances are based on the description of typical European type appliance given by [15], and their technical specifications are given in Table 1 Further, it has been assumed that each house has a renewable power generation system that consists of 14 photovoltaic (PV) solar modules installed on the roof of the home to cover an area of $20 \mathrm{~m}^{2}$, and a small wind turbine installed in the yard. Additionally, the neighborhood receives the energy supplied by an Energy Service Provider (ESP) through the distribution 
Table 1: Technical parameters for typical European smart domestic appliances

\begin{tabular}{ccc}
\hline Appliance & $\begin{array}{c}\text { Energy consumed } \\
(\mathrm{kWh})\end{array}$ & $\begin{array}{c}\text { Cycle time } \\
\text { (hours) }\end{array}$ \\
\hline Washing machine & 0.89 & 1.0 \\
Dishwasher & 1.19 & 1.5 \\
Tumble dryer & 2.46 & 1.0 \\
\hline
\end{tabular}

transformer. It is assumed that the cost of the energy provided by the ESP is based on a Time-of-Use (TOU) pricing scheme, in which the price of the energy varies in different hours of the day depending on peak and off-peak periods. It is given in (1) that establishes three different rates during a day according to the load distribution seen by the transformer.

$$
p(t)=\left\{\begin{array}{cc}
p_{l} & t \in[\text { off-peak hours] } \\
p_{m} & t \in[\text { mid-peak hours] } \\
p_{h} & t \in[\text { peak hours }]
\end{array}\right.
$$

where $p_{l}, p_{m}$ and $p_{h}$ represent the low, medium and high energy price respectively, and $p(t)$ is the price of energy as a function of time $(\mathfrak{f} / \mathrm{kWh})$. In our study, the energy price set by the ESP establishes peak hours to be between $7.00 \mathrm{am}$ to $10.00 \mathrm{am}$ and between $5.00 \mathrm{pm}$ to $8.00 \mathrm{pm}$ with a rate of $0.272 £ / k W h$, mid-peak hours between $10.00 \mathrm{am}$ to $5.00 \mathrm{pm}$ and between $8.00 \mathrm{pm}$ to $11.00 \mathrm{pm}$ with a rate of $0.194 £ / k W h$, and off-peak hours are at night after $11.00 \mathrm{pm}$ until 7.00am with a rate of $0.107 £ / k W h$.

Houses in the neighborhood are enroled in a feed-in tariff program. A feed-in tariff is a payment made to residential energy users for the renewable electricity they generate and export back to the electricity grid. Usually this program is held by governments in order to promote local clean power generation. Any user able to generate electricity from renewable sources is paid a fixed amount of money per kWh generated and an additional incentive per $\mathrm{kWh}$ fed into the grid [16]. In our study the feed-in tariff pays the user $0.370 £ / k W h$ for the electricity generated by renewable sources, and $0.40 £ / k W h$ for the electricity fed back to the grid.

The system is assumed to be supported by a communication infrastructure (wired or wireless). The infrastructure requirement includes a Home Gateway Controller (HGC) at each home that communicates with the appliances. This device registers the activation and energy demanded by appliances and PHEV battery charging, and simultaneously it checks the availability of renewable sources. The HGC can 
communicate with the transformer in order to report the status of a PHEV, including information about charging priority, energy level in the battery and energy demanded by the vehicle. At the transformer a Transformer Gateway Controller (TGC) receives the information reported by the HGC of each home. This information combined with the current power load seen by the transformer is used by the TGC to coordinate the energy demands of the homes in order to prevent the transformer from being overloaded. The TGC holds a coordination mechanism which determines, according to the current situation of the network, the energy assigned to each home and the PHEVs that would be allowed to charge their battery. At homes, appliances make independent request of energy at a random hour of a day when they are activated. Also, PHEVs are plugged in to recharge their battery when they arrive home after a driving day. If the energy demanded by the house cannot be supplied by the renewable sources, it is obtained from the grid.

In this work, we mainly focus on the coordination mechanism to control PHEVs as loads. Communication links are assumed to work ideally without disruption or failures. Communications requirements of the coordination mechanism, including the impact of failures, are addressed in our previous work [11].

\subsection{Mathematical model of the system studied and performance metrics}

In our system, the monetary cost a user has to pay for the energy is equal to the energy provided by the ESP multiplied by the current price of the energy at a specific time. Thus, the daily cost for the user can be expressed as

$$
c_{i}=\sum_{t=1}^{t=24} \sum_{j=1}^{j=m} a_{i, j, t} \cdot p(t)+\sum_{t=1}^{24} g_{i, t} \cdot p(t), \quad \forall i \in[1, h]
$$

where $a_{i, j, t}$ is the energy demanded by appliance $j$ at home $i$ during the hour $t(\mathrm{kWh}), m$ is the number of appliances at home, $g_{i, t}$ is the energy supplied by the distribution transformer to the PHEV's battery at home $i$ during the hour $t$, and $p(t)$ is the price of energy as a function of time $(\mathfrak{f} / \mathrm{kWh})$.

The energy obtained from renewable sources is assumed to be free. However, renewable sources are characterized by a highly intermittent nature due to continuous variations in weather conditions. In the case of wind energy generation, the output power of a wind turbine $W$ is a random variable that mainly 
depends on the wind speed $V$, and can be mathematically modeled as [17, 18]

$$
W(V)= \begin{cases}0 & 0 \leq V<v_{I} \\ \rho \frac{V-v_{I}}{v_{r}-v_{I}} & v_{I} \leq V<v_{r} \\ \rho & v_{r} \leq V<v_{o} \\ 0 & v_{o} \leq V,\end{cases}
$$

where the rated electrical power $\rho$, cut-in wind speed $v_{I}$, rated wind speed $v_{r}$ and cut-out wind speed $v_{o}$ are parameters defined by the wind turbine manufacturer. Variations in wind speed may be represented as a random variable $V$ that is often described by a Weibull distribution [18, 19], with probability density function give by

$$
f_{V}(v)=\frac{K}{C}\left(\frac{v}{C}\right)^{K-1} e^{-\left(\frac{v}{c}\right)^{K}}
$$

where $C$ is the scale parameter and $K$ is the shape parameter. There are different methods described in [19] to estimate the values of these parameters. Among them, the most accurate one, the Statistical Estimation Method, specifies that $C$ and $K$ can be obtained as follows,

$$
K=\left(\frac{\sigma}{\mu}\right)^{-1.086}, \quad C=\frac{\mu}{\Gamma(1+1 / K)}
$$

where $\mu$ and $\sigma$ are the mean and standard deviation of the wind speed obtained from statistical records respectively and $\Gamma(x)$ is the gamma function.

In reference to solar generation, the output energy primarily depends on the solar intensity, the efficiency of the PV panels and their effective area. Therefore, the energy provided by the solar source in intervals of one hour is modeled as

$$
\alpha=S t a ̂ \eta
$$

where $S$ is the solar radiation intensity $\left(\mathrm{kW} / \mathrm{m}^{2}\right), t$ is the time interval in hours considered ( $t=1$ hour), and $\hat{a}$ and $\eta$ are the effective area $\left(\mathrm{m}^{2}\right)$ and efficiency of the PV panels respectively.

Every $\mathrm{kWh}$ generated by the renewable sources leads to a monetary profit to the user. The feed-in program sets a fixed tariff for the energy generated by the renewable electricity system plus an additional price for the energy fed back to the grid. If the tariff considered for the energy generated is $\tau_{g}$ and the tariff considered for the energy fed into the grid is $\tau_{f}$, where $\tau_{f}>\tau_{g}$, the daily profit a user receives from 
the renewable system can be modeled as

$$
\varrho_{i}=\sum_{t=1}^{24}\left(W_{t}+\alpha_{t}\right) \cdot \tau_{g}+\sum_{t=1}^{24} \Delta_{i, t} \cdot \tau_{f}, \quad \forall i \in[1, h]
$$

where $\Delta_{i, t}$ represents the difference between the energy generated by the renewable sources and the energy demanded by home $i$ at hour $t$ (only when the energy from renewable sources is greater than the energy demanded, otherwise $\Delta_{i, t}$ is zero).

The PHEV demand of energy and charging process depend on the battery specifications and daily driving habits of users. Generally, the battery defines a maximum and minimum level of energy $e_{\max }$ and $e_{\min }$ respectively, and the initial state of charge when the vehicle is connected to the grid is a fraction of the full capacity that depends on the distance traveled by the car. Thus, the initial state of charge of the battery can be modeled as a function of the distance traveled as follows

$$
E(D)= \begin{cases}e_{\max } & D=0 \\ e_{\max }-(D \xi) & 0<D<d_{\max } \\ e_{\min } & D \geq d_{\max },\end{cases}
$$

where $d_{\max }$ is the maximum distance the PHEV can travel in electric mode, $D$ represents the distance traveled by the car before plugged into the grid and $\xi$ is the electric efficiency of the car (i.e. the battery energy consumed per unit distance traveled). The daily distance traveled by a vehicle has been modeled based on the average distance traveled by trip length in Great Britain in 2009 [20], through a probability density function given by

$$
\begin{aligned}
p_{D}(d)= & 0.018 u(d-1.5)+5.4 \times 10^{-3} u(d-3) \\
& -1.9 \times 10^{-3} u(d-8)-9.67 \times 10^{-3} u(d-16) \\
& -7.855 \times 10^{-3} u(d-40)-9.625 \times 10^{-4} \\
& u(d-80)-3.0125 \times 10^{-3} u(d-160),
\end{aligned}
$$

where $u(d)$ is the unit step function. And the plug-in time of PHEVs in the grid is modeled as a discrete 
random variable with probability function given by

$$
p_{T}(t)=\sum_{k=16}^{17} \frac{1}{40} \delta(t-k)+\sum_{k=18}^{20} \frac{3}{10} \delta(t-k)+\sum_{k=21}^{22} \frac{1}{40} \delta(t-k),
$$

where $\delta(x)$ is the delta function. This model has been chosen to represent the arrival time of PHEVs at home, which is more likely at evening time when people return to home after a working day. According to this distribution, vehicles arrive between $4.00 \mathrm{pm}$ to $10.00 \mathrm{pm}$, with a mean at $7.00 \mathrm{pm}$. Normal distributions can also be used for this representation.

The activation time of appliances is based on statistical records of daily load pattern curves for specific appliances in the UK [15]. It has been considered as random variables following the discrete probability distributions shown in Figure2

(a) Washing machine

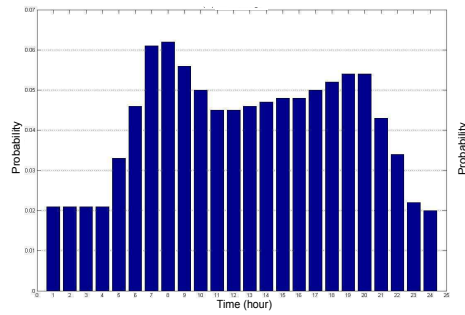

(b) Dish washer

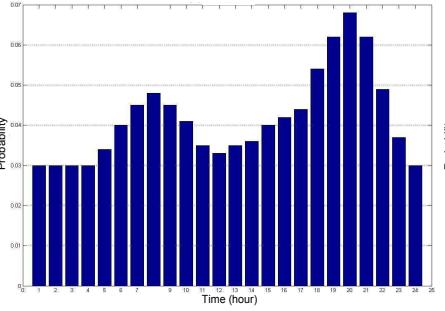

(c) Tumble dryer

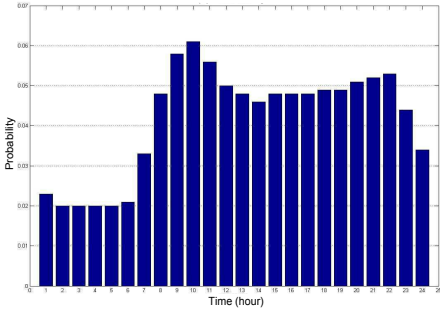

Figure 2: Probability distribution for the activation time of home appliances in the UK: (a) washing machine, (b) dishwasher, and (c) tumble dryer

Finally, in order to measure the performance of the renewable generation system, two efficiency metrics are defined. Firstly, the renewable fraction of a smart home is defined as the ratio between the energy provided by renewable sources and the total energy demanded by a home

$$
\eta_{e i}=\frac{\alpha_{i}+\beta_{i}}{\alpha_{i}+\beta_{i}+\gamma_{i}},
$$

where $\alpha_{i}, \beta_{i}$ and $\gamma_{i}$ are the energy given by the solar, the wind and the grid source respectively for home $i$. This metric quantifies the percentage of energy saving achieved by a user in a month. And secondly, the renewable cost ratio is defined as the ratio between the user saving and the total energy expenses

$$
\eta_{c i}=\frac{f_{i}}{c_{i}+f_{i}},
$$


where $f_{i}$ is the cost saving for home $i$ with renewable sources and $c_{i}$ is the cost paid for the energy consumed at home $i$ with renewable sources. Hence $c_{i}+f_{i}$ would be the energy cost at home $i$ without renewable sources. This metric quantifies the percentage of cost saving a user can obtain by having a renewable system.

\section{Distribution transformer loading and plug-in hybrid electric vehicles}

\subsection{Current distribution system}

A distribution network refers to all the components at the final stage in the delivery of electricity to users. Normally this network is composed of a power substation that steps down the electrical power brought through the transmission lines from $69 \mathrm{kV}$ to $12.47 \mathrm{kV}$, and the residential distribution transformers that step down the voltage to $120 \mathrm{~V}, 240 \mathrm{~V}$ or $480 \mathrm{~V}$. Distribution transformers are the final step in delivering the power to residential and industrial users.

A typical load profile for a $25 \mathrm{kVA}$ distribution transformer serving 5 homes in winter and summer months are shown in Figures 3(a) and 3(b) respectively [4].

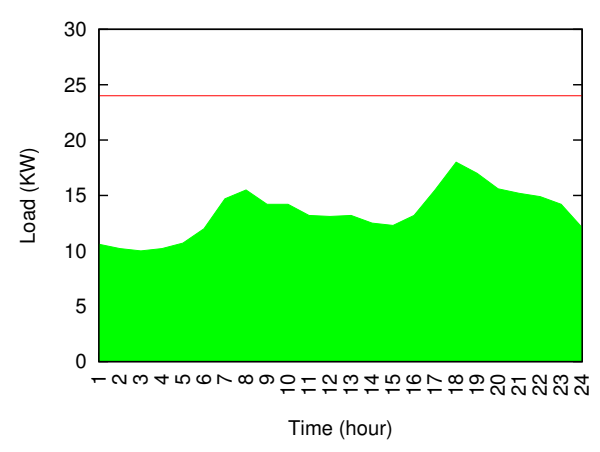

(a) Winter

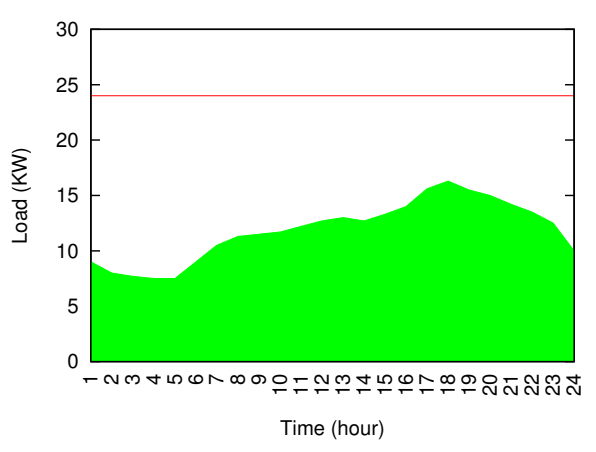

(b) Summer

Figure 3: Load profile for a $25 \mathrm{kVA}$ distribution transformer serving 5 homes

During winter months two main peaks are observed in the load profile, one occurring between 7.00am and $8.00 \mathrm{am}$ in the morning and the other one in the evening between $6.00 \mathrm{pm}$ and $7.00 \mathrm{pm}$. During summer, one main peak is registered around 6.00pm in the evening. We assume that the $25 \mathrm{kVA}$ distribution transformer has a rated power of $23.75 \mathrm{~kW}$ (shown in red dot line in the figures) with a constant power factor of 0.95 and is designed with enough capacity to support the traditional residential loads even during peak times. The load profiles for residential users include the majority of home appliances including 
Table 2: Chevy Volt battery specifications [21]

\begin{tabular}{ll}
\hline Description & Specifications \\
\hline Battery type & Lithium-ion \\
Maximum capacity & $16 \mathrm{kWh}$ \\
Voltage & 320 to $350 \mathrm{~V}$ \\
Current & $15 \mathrm{~A} @ 120 \mathrm{~V}$ or $30 \mathrm{~A} @ 240 \mathrm{~V}$ \\
Full charge time & 4 hours @ 240V \\
Maximum charging power & $3.3 \mathrm{~kW}$ \\
Electric range & $64 \mathrm{~km}(40 \mathrm{miles})$ \\
Electric efficiency & $0.25 \mathrm{kWh} / \mathrm{km}(0.4 \mathrm{kWh} / \mathrm{mile})$ \\
\hline
\end{tabular}

space cooling/heating, water heating, clothes washers/dryers, freezing, lighting, cooking, etc. Under this circumstance a transformer is approximately loaded at about $75 \%$ in winter and $68 \%$ in summer for the worse case scenario (during peak time).

\subsection{Impact of plug-in hybrid electric vehicles}

A high penetration of PHEVs in the vehicle market is envisioned to have a negative impact on the current distribution system. Charging multiple PHEV batteries on the distribution grid without any coordination, particularly during the evening time when people arrive home after work, could compromise the current capacity of the distribution transformer. This depends on the charging characteristics of the vehicles and the plug-in time.

For the purpose of this study, the PHEV battery model considered is based on the specifications of the Chevy Volt 2011 summarized in Table 2. Chevy Volt is a hybrid sedan that combines electric and gas powered engine with a typical electric driving range of $64 \mathrm{~km}$. The vehicle can be plugged into the grid to recharge its battery in two different modes, at $110 \mathrm{~V}$ and $240 \mathrm{~V}$. For the purpose of this work, as a matter of simplification, it has been assumed that PHEVs are only charged in Quick Charge mode at 240 $\mathrm{V}$, demanding the maximum charging power.

We add PHEV loads to the residential load profile shown in Figures 3(a) and 3(b) PHEVs are randomly plugged into the grid following a discrete probability distribution (as discussed in the previous section). Figures 4(a) and 4(b) illustrate the average hourly load profile seen by the transformer when PHEVs are part of the loads. In both cases the rated power is exceeded during the evening peak time. The winter profile shows the rated power is exceeded for around two hours between $7.00 \mathrm{pm}$ and $9.00 \mathrm{pm}$, and the transformer is overloaded by $116 \%$ at the highest peak. The summer profile (Figure 4(b) shows the transformer is overloaded by $111 \%$ at $8.00 \mathrm{pm}$. 


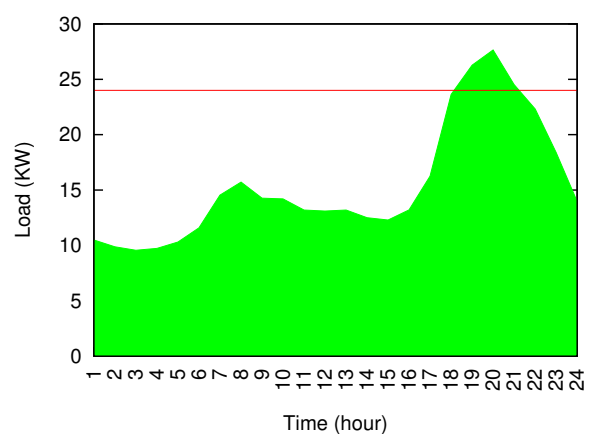

(a) Winter

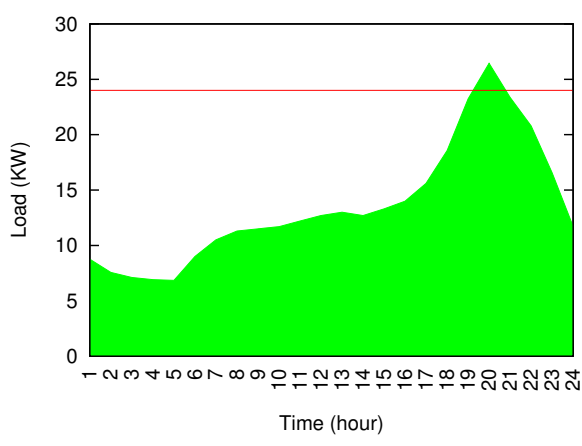

(b) Summer

Figure 4: Load profile for a 25kVA distribution transformer serving 5 homes and 5 PHEVs without load control mechanism

The initial results from the simulation have revealed that having multiple PHEVs charging their battery simultaneously from the grid can overload the transformer even when having a renewable power generation system at home, with negative effects on the transformer such as reduced service lifetime, reduced efficiency, variations in the voltage regulation, frequency instability, etc. In this case, two possible solutions may emerge: upgrading the distribution system or implementing load control mechanisms to avoid overloading the transformer. However, the first option seems to be more costly in most of the cases due to the large number of transformers installed in a typical network. Therefore, implementing coordination mechanisms is considered a more feasible solution. Our proposed mechanism is introduced in the next section.

\section{Load coordination mechanism}

The load coordination mechanism proposed in this work is based on periodic communications between the homes and the transformer in order to check the current status of the loads. A DR strategy is also considered. The coordination mechanism assumes PHEV charging is the main reason leading to overload of the distribution transformer, as discussed earlier. Hence, the mechanism manages the charging time of vehicles, delaying it when required, in order to prevent the rated power of the transformer to be exceeded. The charging preference of the user is taken into account by giving him/her two options: charge immediately or delay charging ${ }^{1}$ The first option prioritizes the vehicle charging among its neigh-

\footnotetext{
${ }^{1}$ We note that more sophisticated priority schemes can also be devised.
} 
bors and the PHEV is charged during peak hours, which is associated with higher energy prices. Hence charging time can be reduced but monetary cost may increase. This option is referred to as charging with priority in the rest of the paper. The second option delays PHEV charging to off-peak hours, avoiding higher energy prices. This option is referred to as charging without priority, and can lead to more cost savings but requires longer charging time. The motivation for a user to select one of the two charging options is based on the user's interest on whether to save money by avoiding peak pricing periods and delaying battery charging, or try to finish the charging process as quickly as possible at the expense of increased cost.

The coordination mechanism relies on two main infrastructure elements, a HGC and a TGC. These elements operate in hourly time slots.

The operation of the HGC is illustrated in Figure 5. The HGC monitors the energy demanded by the different appliances and the PHEV, and adds it to the rest of the energy demand of the house to determine the total energy demand at a given time. Simultaneously, the HGC checks the energy being generated by the solar and wind sources, and combines them to determine the energy provided by renewable sources. Then, the HGC compares the total energy demand with the energy locally generated. In case the demand exceeds the renewable capacity the difference is requested from the grid, otherwise the difference is fed back to the grid. After processing all these information the HGC transmits a report to the TGC in the transformer. This report includes the following information regarding the status of PHEVs: whether it is connected to the grid or not, the energy demanded by the PHEV, the current energy in PHEV's battery, and whether the PHEV has priority in charging.

The TGC receives the report sent by each home and combines their information with the total load currently seen by the transformer to determine the current load situation of the residential grid. The total load is compared with the transformer rated power, and if it does not exceed this capacity then the transformer supplies the energy requested by each home. On the other hand, if the total load is greater than the rated power, the TGC activates the coordination mechanism algorithm to identify which PHEVs must be deferred from charging their battery at that time interval. As discussed in Section 3 overloading is mainly caused by PHEV charging, therefore this is the only load to be managed and shifted in time. Figure 6 shows the flowchart of the coordination mechanism implemented at the TGC.

The TGC coordination algorithm has the purpose of determining which vehicles are allowed to charge during this time interval and which are not, according to a defined policy. The basic policy used in our 


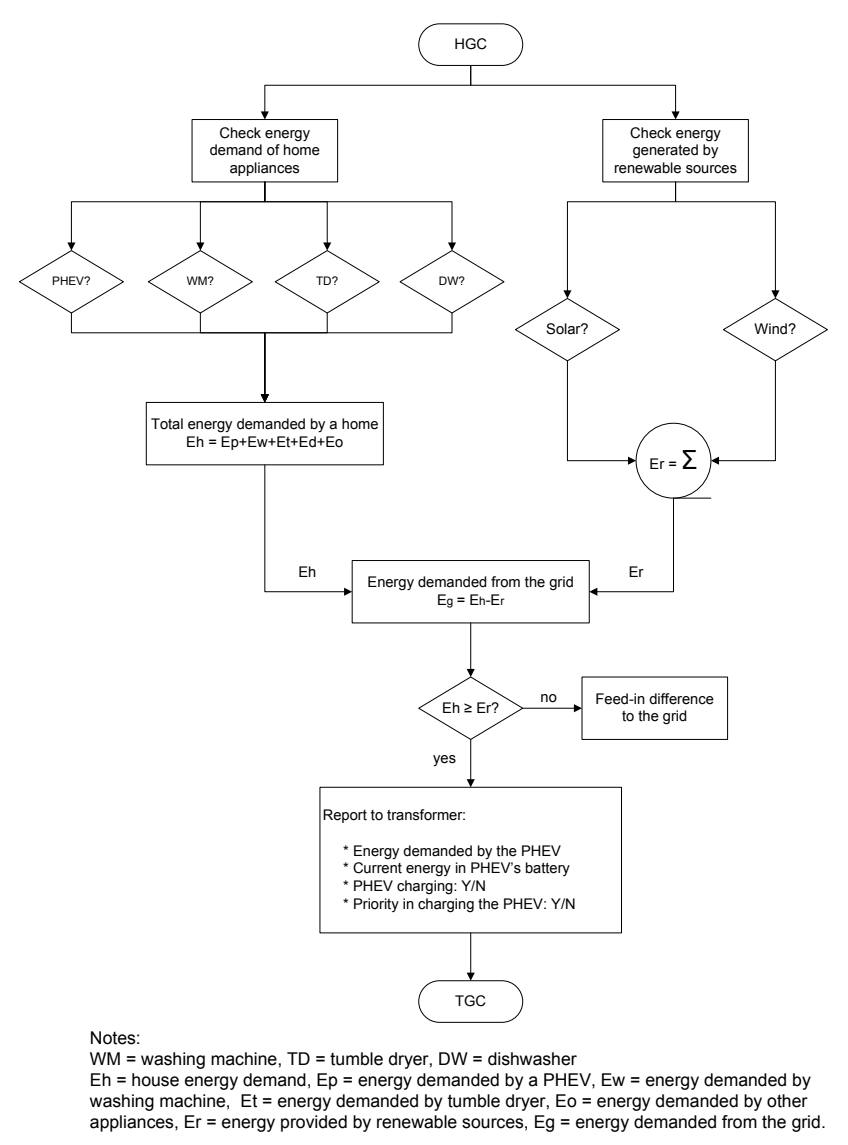

Figure 5: HGC coordination mechanism flowchart

study establishes that the selection is based on the information about the priority on charging the battery and the current energy level in the battery. Based on the total load, the information provided by each HGC, and the rated power of the transformer, the TGC estimates the maximum number of PHEVs that can be charged simultaneously. When there are more PHEVs requesting charging than the system can accommodate, firstly those PHEVs without priority are postponed to charge their batteries during offpeak periods. And if there are some PHEVs with priority that also need to be delayed, re-scheduling of the charging operation is done based on the current level of energy in the battery. Those PHEVs with less energy in their batteries are charged first. This policy has been chosen for simplicity, but without loss of generality other policies can also be defined to do the selection more efficiently.

The output of the TGC is a report message that contains the current electricity price, the energy assigned to each home, and the decision of whether to charge the PHEV or not. A specific report is 


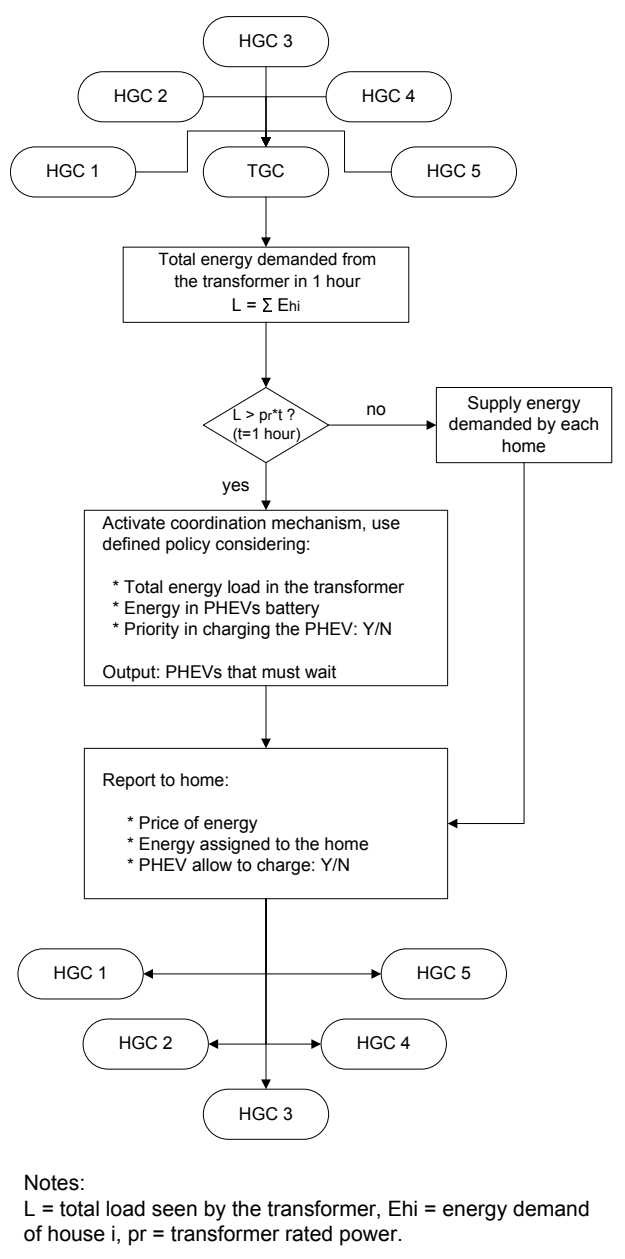

Figure 6: TGC coordination mechanism flowchart

forwarded to each home, where the HGC is responsible for setting the parameters defined by the TGC. In this sense, our load coordination mechanism is independent of the specific electricity pricing scheme considered.

\section{Simulation results}

Monte Carlo simulations have been performed in order to evaluate different aspects of the system. This requires to develop a mathematical model of the system, which has been implemented through a computational model in Matlab. Simulations have been oriented to obtain results that allow us to analyze the performance of the proposed coordination mechanism, as well as the impact of renewable sources in 
the system.

Figures $7(\mathrm{a})$ and $7(\mathrm{~b})$ show the average load profile including PHEV charging for winter and summer months respectively, when the coordination mechanism is used. When comparing these figures with the profiles shown in Figures 4(a) and 4(b), it can be seen that the peak exceeding the rated power at evening hours is avoided, and part of the energy is shifted from $7.00 \mathrm{pm}$ to $11.00 \mathrm{pm}$ and $12.00 \mathrm{pm}$. The coordination mechanism is able to shift the loads registered during the evening peak time to later hours, hence preventing overload in the distribution transformer.

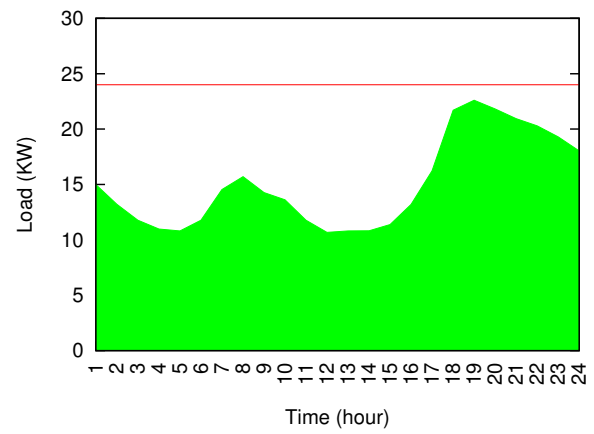

(a) Winter

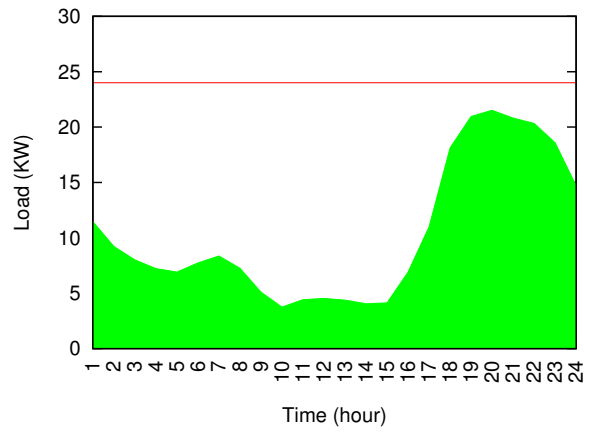

(b) Summer

Figure 7: Load profile for a $25 \mathrm{kVA}$ distribution transformer serving 5 homes and 5 PHEVs with load control mechanism

In order to exemplify the performance of the coordination mechanism, we consider a worse case scenario. The scenario assumes all the PHEVs are plugged into the grid between $5.00 \mathrm{pm}$ and $7.00 \mathrm{pm}$ when people arrive at home after a working day. PHEVs in homes 1, 2 and 5 have chosen priority in the charging process, while PHEVs in homes 3 and 4 have not. Several appliances in different houses are activated during that period too. The simulation have been conducted using data for a winter month (January). The load profile registered for this scenario is shown in Figure 8(a) Without any control mechanism the load added by 5 PHEVs produces a peak at 7.00pm that overloads the transformer by $152 \%$ for nearly an hour.

With the proposed coordination mechanism, the new load profile is shown in Figure 8 (b) This figure illustrates how the mechanism shifts the peak load to later hours by postponing the battery charging of those PHEVs that are connected without priority (PHEV 3 and PHEV 4). Therefore, the transformer is prevented from being overloaded. The coordination mechanism controls PHEV charging whenever it detects a potential overloading in the distribution transformer. For this particular case, the critical period 


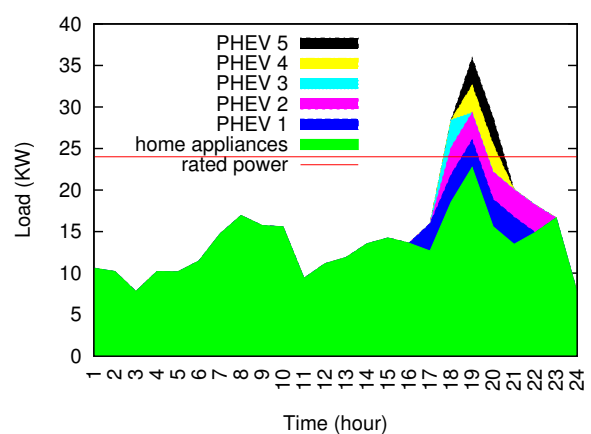

(a) Without control

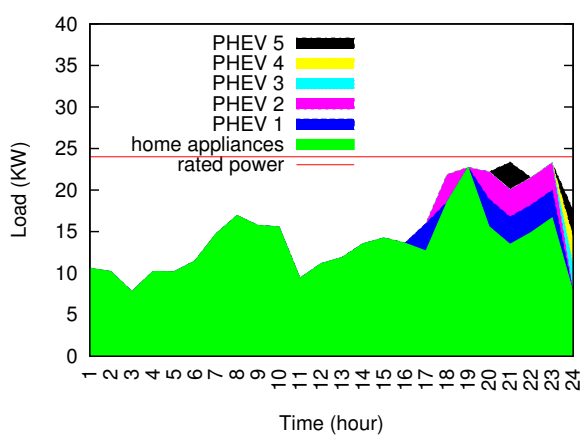

(b) With control

Figure 8: Load profile for a $25 \mathrm{kVA}$ distribution transformer in a worse case scenario

to be managed is during hours $5.00 \mathrm{pm}$ to $11.00 \mathrm{pm}$, since all the vehicles are connected to the grid between $5.00 \mathrm{pm}$ to $7.00 \mathrm{pm}$.

\subsection{Impact of the coordination mechanism on user's convenience}

Since the proposed coordination mechanism is based on PHEV load management only, the impact on the usage of other appliances is minimum. It does not turn off appliances. Thus, the impact on user convenience may be analyzed from the perspective of the time the user has to wait for his vehicle to be totally charged.

According to specifications of the Chevy Volt, the vehicle's battery can be normally charged in the current electricity grid in approximately four hours at $240 \mathrm{~V}$ (without coordination mechanism) [21]. Here we consider the average maximum time a user has to wait to charge his PHEV (from it is plugged into the grid till the battery is fully charged) using two charging modes - with and without priority, for both winter and summer seasons. Results for winter and summer are shown in Figures 9(a) and 9(b) respectively. These figures illustrate the maximum charging time for a vehicle as a function of the initial battery charge when they are connected to the grid. In both cases, the charging time is a decreasing step function, with a difference of roughly two hours between summer and winter. Obviously the less initial energy a battery has, the longer it takes to fully charge it. The higher contribution of solar power generation during summer increase the renewable fraction at home, thus reducing the maximum charging time. Also, charging with priority contributes to reduce the total charging time compared with charging without priority which incurs more waiting time. 


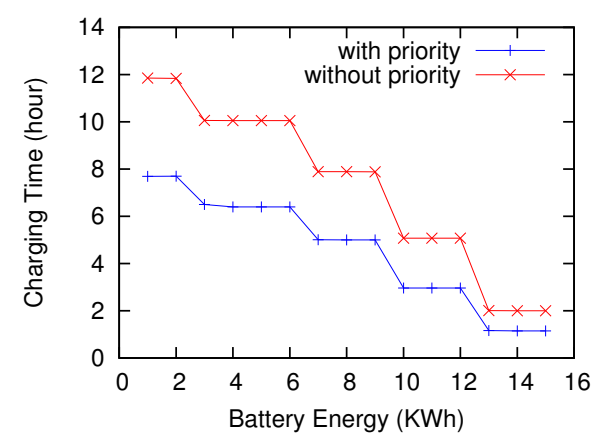

(a) Winter

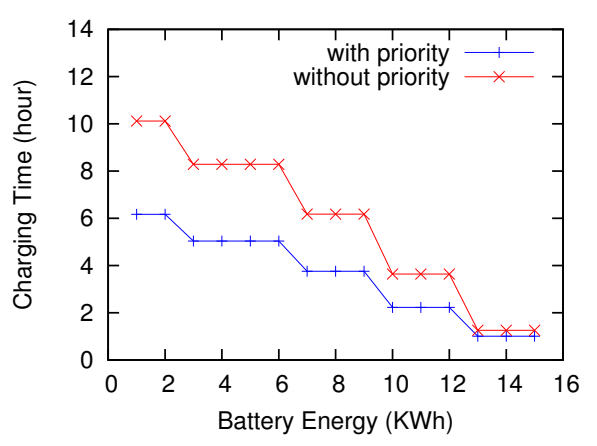

(b) Summer

Figure 9: Maximum PHEV charging time as a function of the initial battery charge

It is worthwhile to mention that the results shown have been obtained for the scenario in which users plug their vehicles into the grid between $4.00 \mathrm{pm}$ to $10.00 \mathrm{pm}$. Therefore, if the charging process occurs during the night, users would have enough time to fully charge their batteries before they need to use their cars the following morning for most of the cases (here we assume the user leaves home around 7-8am). This suggests user convenience would not be significantly affected.

\subsection{Impact of renewable sources in the system studied}

The renewable power generation system installed at each smart home consists of a group of PV panels and a wind turbine. The PV generates electricity from solar radiation, which has been represented using data from the SoDa database for different months in 2005 [22]. The radiation values are obtained for panels facing the south, with 40 degrees inclination angle, at elevation of $11 \mathrm{~m}$ from sea level, geographically located at a latitude of $51.45^{\circ}$ North and longitude of $2.58^{\circ}$ West (City of Bristol, UK). The technical specifications of the PVs used in our analysis are presented in Table 3(a).

Regarding generation with wind turbine, the wind speed records of Bristol in 2008 and 2009 collected by [23] are used to determine the average and standard deviation of wind speed for different seasons in a year. The specifications of the wind turbine considered in the model are shown in Table $3(\mathrm{~b})$, based on parameters defined by some wind turbine manufacturers.

Figure 10 depicts the distribution of energy provided by different sources during the months January, April, July and October. These months are selected to represent different seasons of the year. For all of the evaluated months, the greatest amount of energy is always provided by the grid. The energy provided by the renewable sources is highly dependent on the season. During January, when solar radiation is 
Table 3: Technical specifications for wind turbine and PV panels

(a) PV module

\begin{tabular}{lc}
\hline \multicolumn{1}{c}{ Description } & Specifications \\
\hline Model & Sanyo H250E01 \\
Max. Power & $250 \mathrm{~W}$ \\
Max. Efficiency & $18 \%$ \\
Output power & $180 \mathrm{~W} / \mathrm{m}^{2}$ \\
Module area & $1.386 \mathrm{~m}^{2}$ \\
\hline
\end{tabular}

(b) Wind turbine

\begin{tabular}{lc}
\hline \multicolumn{1}{c}{ Description } & Specifications \\
\hline Model & HY-3000 \\
Rated power & $3000 \mathrm{~W}$ wind \\
Rated speed & $28 \mathrm{mph}$ or $12.5 \mathrm{~m} / \mathrm{s}$ \\
Cut-in speed & $<6.7 \mathrm{mph}(3 \mathrm{~m} / \mathrm{s})$ \\
Rated voltage & DC $48 \mathrm{~V}$ \\
Max power (wind only) & $3500 \mathrm{~W}$ \\
\hline
\end{tabular}

weaker and daylight is shorter, the energy provided by PV panels reaches its minimum and the majority of renewable power comes from the wind. During April and July, solar radiation significantly increases in the northern hemisphere. Consequently, the solar power generation rises during those two months.

(a) January (Winter)

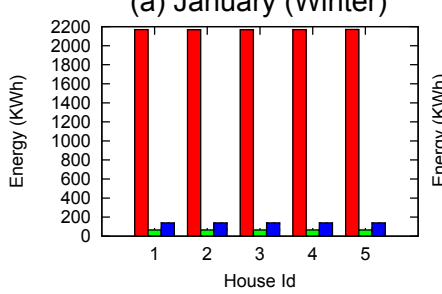

(c) July (Summer)

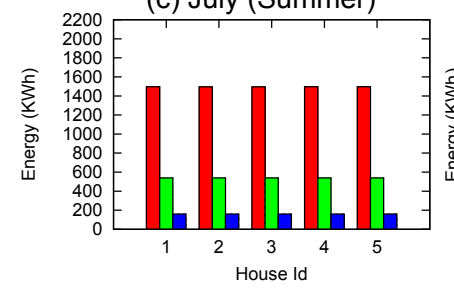

(b) April (Spring)

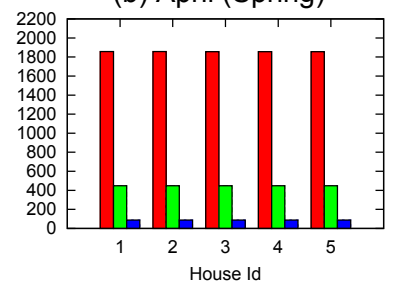

(d) October (Autumn)

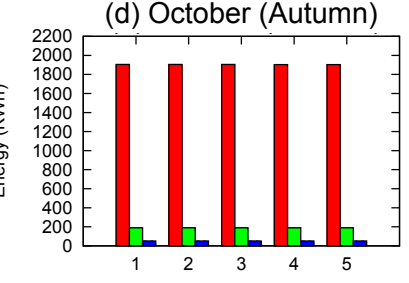

House Id

Figure 10: Energy provided by different sources in a home during a month: (a) January, (b) April, (c) July, and (d) October

The renewable fraction value in a smart home depends on the climatic conditions (e.g. different seasons) in the region evaluated. The renewable fraction for a smart home in different seasons of the year is shown in Figure 11 The highest average renewable fraction is obtained for July, indicating that during this month more renewable energy is available to address the energy demand of a home. This reduces costs to the user and, at the same time, increases the profit received via the feed-in tariff. Figure 12 shows the renewable cost ratio for a smart home when charging the PHEV with and without priority. From this figure it can be seen that charging the vehicle always with priority can reduce the renewable cost ratio of 
the system, which means less monetary saving for the user. Charging without priority can increase the renewable cost ratio of the system by approximately $10 \%$ during any season of the year.

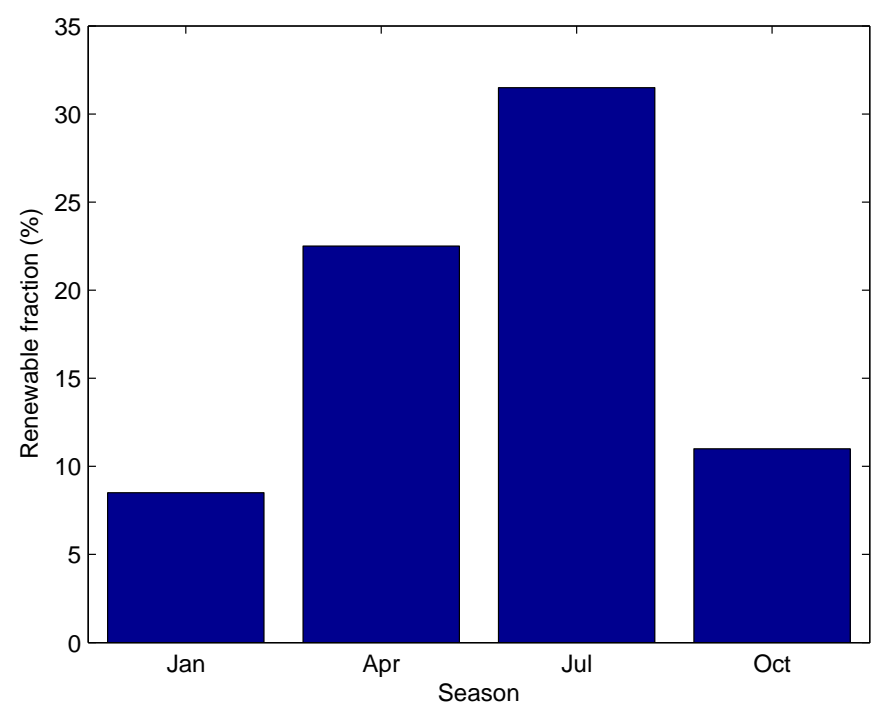

Figure 11: Renewable fraction

\subsection{Profits and economic benefits of the renewable system}

The main economic benefits derived from the renewable system include monthly cost saving and monthly profit. The cost saving refers to a cut in electricity bills, due to the energy used from renewable sources rather than the grid. The profit refers to the money received from the feed-in tariff for the electricity locally generated and fed to the grid. This has been mathematically represented in Equation (7).

Figure 13 shows the average monthly saving per home obtained in different seasons of the year (in sterling pound, or GBP). It should be pointed out that for homes 1, 2 and 5, PHEVs are always connected with priority in charging their battery, while in homes 3 and 4, PHEVs are connected without priority. For all homes, economic saving is higher during spring and summer, when solar radiation increases. For all seasons, charging PHEVs without priority leads to higher monetary saving in electricity bills when compared to the case when PHEVs are charged with priority.

The average profit obtained from local renewable generation and the energy fed back to the grid is as follows: $£ 75.70$ for January, $£ 206.40$ for April, $£ 278.17$ for July, and $£ 89.45$ for October. The minimum profit is obtained during winter season, when renewable generation is also minimum (see Figure 10 . 


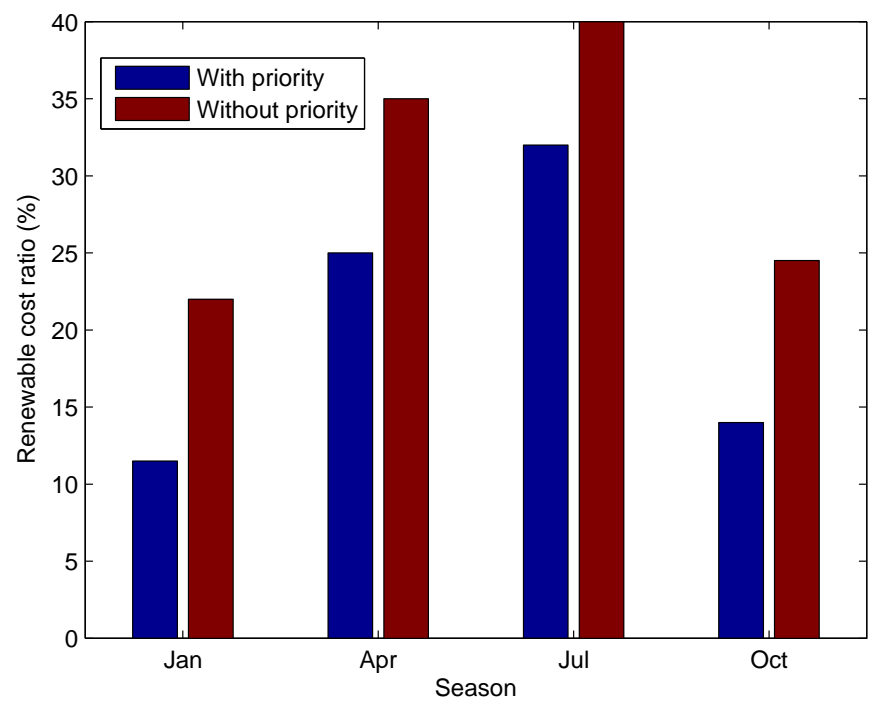

Figure 12: Renewable cost ratio

During spring and summer months, the average profit can increase by up to $367 \%$ in comparison with winter, and it is reduced again in autumn.

\subsection{Discussion}

In this section we briefly discuss a number of relevant issues. So far a lot papers in the literature (including the current paper) have discussed the technical challenges and solutions for PHEV integration into the grid. However, a large scale adoption of electric vehicles also very much depends on various economic factors. In [24], we present an economic analysis of electric vehicles (EVs) based on comparisons with conventional vehicles to determine the economic and environmental benefits offered by EVs from a user's perspective. Our findings show that EVs can help to reduce energy cost and emissions. However, the retail cost of EVs still needs to decrease for EVs to become economically attractive for users.

We would like to point out that PHEV charging coordination can be formulated as different optimization problems according to different objective functions, e.g., cost minimization, or load leveling. In contrast to the centralized solution in this paper, there are also distributed ones such as those based on game theory. The main focus of this paper, however, is to show that it is possible to design a simple and effective mechanism that avoids overloading the transformer and in the meantime satisfies user preference. 


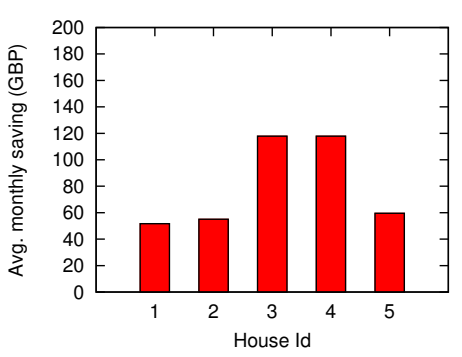

(a) January

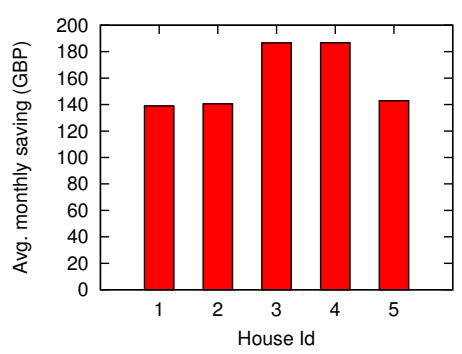

(c) July

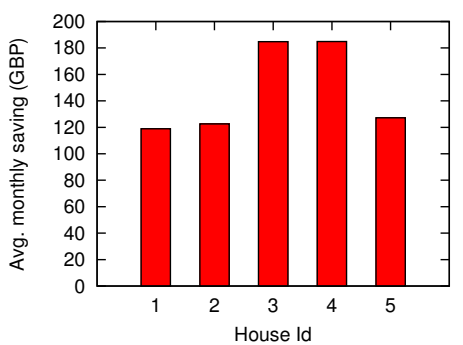

(b) April

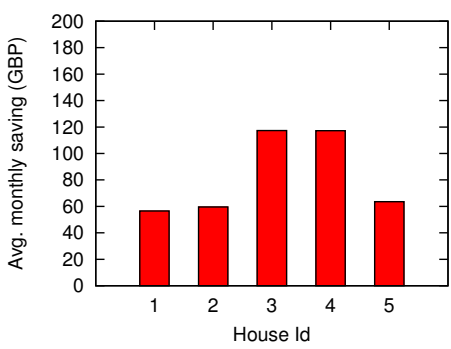

(d) October

Figure 13: Monthly cost saving in a smart home

\section{Conclusions}

Without coordination, a high penetration of PHEVs in the vehicle market can lead to stress in the residential distribution systems, particularly when several vehicles are plugged into the grid at peakevening hours. To address this challenge, the distribution system needs to be adapted to support the new loads. The evolution of traditional electricity grids to smart grids will allow implementation of coordination mechanisms that control PHEV charging in order to prevent distribution transformer from being overloaded.

In this paper, a coordination mechanism has been introduced to manage PHEV charging by shifting the charging time of some vehicles from peak hours to off-peak hours. It has been shown that the mechanism is able to prevent the load profile to exceed the transformer rated power even for a worse case scenario. The impact of the coordination mechanism on user convenience has been considered in terms of the time a user needs to wait for his/her vehicle to be fully charged. It has been found that the maximum waiting time can be covered during night hours, and PHEV battery will be ready by next morning. The energy efficiency and cost efficiency of the renewable system depend on many factors, e.g. weather, region, equipment specification, user preference, etc. Efficiencies are higher in those seasons with higher 
solar radiation and wind speed.

\section{Bibliography}

[1] Z. Fan, P. Kulkarni, S. Gormus, C. Efthymiou, G. Kalogridis, M. Sooriyabandara, Z. Zhu, S. Lambotharan, and W. H. Chin, "Smard grid communications: Overview of research challenges, solutions, and standardization activities," IEEE Communications Surveys and Tutorials, vol. 15, no. 1, 2013.

[2] W. Su, H. Rahimi-Eichi, W. Zeng, and M.-Y. Chow, "A survey on the electrification of transportation in a smart grid environment," IEEE Transactions on Industrial Informatics, vol. 8, no. 1, February 2012.

[3] A. Sheikhi, S. Bahrami, M. Ranjbar, and H. Oraee, "Strategic charging method for plugged in hybrid electric vehicles in smart grids: a game theoretic approach," International Journal of Electrical Power and Energy Systems, vol. 53, December 2013.

[4] S. Shao, M. Pipattanasomporn, and S. Rahman, "Challenges of PHEV penetration to the residential distribution network," IEEE Power and Energy Society General Meeting, pp. 1-8, September 2009.

[5] — - "Demand response as a load shaping tool in an intelligent grid with electric vehicles," IEEE Transactions on Smart Grid, vol. 2, no. 4, pp. 624-631, December 2011.

[6] L. P. Fernandez, T. G. S. Roman, R. Cossent, M. Domingo, and P. Frias, "Assessment of the impact of plug-in electric vehicles on distribution networks," IEEE Transactions on Power Systems, vol. 26, no. 1, pp. 206-213, February 2011.

[7] S. Vandael, N. Boucke, T. Holvoet, and G. Deconinck, "Decentralized demand side management of plug-in hybrid vehicles in a smart grid," in AAMAS ATES Workshop, 2010.

[8] M. Caramanis and J. Foster, "Management of electric vehicle charging to mitigate renewable generation intermittency and distribution network congestion," in IEEE CDC, 2009.

[9] M. Erol-Kantarci and H. Mouftah, "Management of PHEV batteries in the smart grid: towards a cyber-physical power infrastructure," IEEE Workshop on Design, Modeling and Evaluation of Cyber Physical Systems, pp. 795-800, July 2011.

[10] T. Hammons, "Integrating renewable energy sources into European grids," International Journal of Electrical Power and Energy Systems, vol. 30, October 2008.

[11] R. M. Oviedo, Z. Fan, S. Gormus, P. Kulkarni, and D. Kaleshi, "Residential energy demand management in smart grids," IEEE PES Transmission and Distribution Conference and Exposition, May 2012.

[12] A. Brooks, E. Lu, D. Reicher, C. Spirakis, and B. Weihl, "Demand dispatch," IEEE Power and Energy Magazine, pp. 20-29, May/June 2010.

[13] R. Aazamia, K. Aflakib, and M. Haghifam, "A demand response based solution for LMP management in power markets," International Journal of Electrical Power and Energy Systems, vol. 33, June 2011.

[14] N. Gudi, L. Wang, and V. Devabhaktuni, "A demand side management based simulation platform incorporating heuristic optimization for management of household appliances," International Journal of Electrical Power and Energy Systems, vol. 43, December 2012. 
[15] R. Stamminger, Synergy Potential of Smart Appliances. D2.3 of WP2 from the Smart-A project. University of Bonn, Germany, November 2008.

[16] Feed-in Tariffs [Online]. Available: http://www.fitariffs.co.uk/.

[17] B. Jatzeck, A. Robinson, and D. Koval, "Estimation of the optimum rated wind velocity for wind turbine generators in the vicinity of Edmonton, Alberta," Proceedings of the 1999 IEEE Canadian Conference on Electrical and Computer Engineering, 1999.

[18] K. Qian, C. Zhou, Z. Li, and Y. Yuan, "Benefits of energy storage in power systems with high level of intermittent generation," 20th International Conference on Electricity Distribution, no. 0358, June 2009.

[19] D. Wei, C. Jichuan, and F. Hengchang, "Comparative research on methods of calculating Weibull distribution parameters of wind speed," IEEE APPEEC, 2011.

[20] National Travel Survey 2009. Department for Transport Statistics [Online]. Available: http://www.dft.gov.uk/pgr/statistics. Last accessed in July 2011.

[21] Chevy Volt [Online]. Available: http://www.chevrolet.com/volt.

[22] Solar Radiation Data Service (SoDa). HelioClim-3 database 2005 [Online]. Available: http://www.soda-is.com/eng/index.html. Last accessed in July 2011.

[23] The weather records of Bristol [Online]. Available: http://www.afour.demon.co.uk/weather.htm. Last accessed in July 2011.

[24] R. M. Oviedo, Z. Fan, S. Gormus, and P. Kulkarni, "The reign of EVs? an economic analysis from user's perspective," submitted to IEEE VT Magazine, Jan 2013. 